\title{
The neural processing of foreign-accented speech and its relationship to listener bias
}

\author{
Han-Gyol Yi ${ }^{1}$, Rajka Smiljanic ${ }^{2}$ and Bharath Chandrasekaran ${ }^{1,3 *}$ \\ ' SoundBrain Lab, Department of Communication Sciences and Disorders, Moody College of Communication, The University of Texas at Austin, Austin, TX, USA \\ ${ }^{2}$ UT Sound Lab, Department of Linguistics, College of Liberal Arts, The University of Texas at Austin, Austin, TX, USA \\ ${ }^{3}$ Institute for Neuroscience, The University of Texas at Austin, Austin, TX, USA
}

\section{Edited by:}

Carolyn McGettigan, Royal Holloway

University of London, UK

Reviewed by:

Patti Adank, University College

London, UK

Daniel A. Abrams, Stanford

University, USA

\section{${ }^{*}$ Correspondence:}

Bharath Chandrasekaran

SoundBrain Lab, Department of

Communication Sciences and

Disorders, Moody College of

Communication, The University of

Texas at Austin, 1 University Station,

C7000, 2504A Whitis Ave. (A1100),

Austin, TX 78712, USA

e-mail: bchandra@utexas.edu
Foreign-accented speech often presents a challenging listening condition. In addition to deviations from the target speech norms related to the inexperience of the nonnative speaker, listener characteristics may play a role in determining intelligibility levels. We have previously shown that an implicit visual bias for associating East Asian faces and foreignness predicts the listeners' perceptual ability to process Korean-accented English audiovisual speech (Yi et al., 2013). Here, we examine the neural mechanism underlying the influence of listener bias to foreign faces on speech perception. In a functional magnetic resonance imaging (fMRI) study, native English speakers listened to native- and Korean-accented English sentences, with or without faces. The participants' Asian-foreign association was measured using an implicit association test (IAT), conducted outside the scanner. We found that foreign-accented speech evoked greater activity in the bilateral primary auditory cortices and the inferior frontal gyri, potentially reflecting greater computational demand. Higher IAT scores, indicating greater bias, were associated with increased BOLD response to foreign-accented speech with faces in the primary auditory cortex, the early node for spectrotemporal analysis. We conclude the following: (1) foreign-accented speech perception places greater demand on the neural systems underlying speech perception; (2) face of the talker can exaggerate the perceived foreignness of foreign-accented speech; (3) implicit Asian-foreign association is associated with decreased neural efficiency in early spectrotemporal processing.

\section{Keywords: foreign-accented speech, speech perception, fMRI, implicit association test, neural efficiency, primary} auditory cortex, inferior frontal gyrus, inferior supramarginal gyrus

\section{INTRODUCTION}

Foreign-accented speech (FAS) can constitute an adverse listening condition (Mattys et al., 2012). Perception of FAS is often less accurate and more effortful compared to native-accented speech (NAS; Munro and Derwing, 1995b; Schmid and Yeni-Komshian, 1999; Van Wijngaarden, 2001). The reduced FAS intelligibility has been attributed to deviations from native speech in terms of segmental (Anderson-Hsieh et al., 1992; Van Wijngaarden, 2001) and suprasegmental (Anderson-Hsieh and Koehler, 1988; Anderson-Hsieh et al., 1992; Tajima et al., 1997; Munro and Derwing, 2001; Bradlow and Bent, 2008) cues. Nevertheless, listeners can adapt to FAS following exposure or training (Clarke and Garrett, 2004; Bradlow and Bent, 2008; Sidaras et al., 2009; Baese-Berk et al., 2013). Thus, listener's perception of FAS perception can improve over time (Bradlow and Pisoni, 1999; Bent and Bradlow, 2003). The neuroimaging literature on FAS perception is scant. However, perception of foreign phonemes has been shown to engage multiple neural regions. These include the superior temporal cortex, which matches the auditory input to the preexisting phonological representations ("signal-to-phonology mapping") in the articulatory network, encompassing the motor cortex, inferior frontal gyrus, and the insula (Golestani and
Zatorre, 2004; Wilson and Iacoboni, 2006; Hickok and Poeppel, 2007; Rauschecker and Scott, 2009). In particular, the inferior frontal gyrus exhibits phonetic category invariance, in which the response patterns differ according to between-category phonological variances but not to within-category acoustical variances (Myers et al., 2009; Rauschecker and Scott, 2009; Lee et al., 2012). Accordingly, processing of artificially distorted speech which, reduces speech intelligibility but does not necessarily introduce novel phonological representations, has been shown to involve additional recruitment of the superior temporal areas, the motor areas, and the insula, but not the inferior frontal gyrus (for review, see Adank, 2012). These findings lead to two predictions regarding neural activity during FAS processing. First, lack of adaptation to FAS would manifest in increased activity in the superior temporal auditory areas, due to the increased demand on auditory input processing. The primary auditory cortex is sensitive not only to rudimentary acoustic information such as frequency, intensity, and complexity of the auditory stimuli (Strainer et al., 1997), but also to the stochastic regularity in the input (Javit et al., 1994; Winkler et al., 2009) and attention (Jäncke et al., 1999; Fritz et al., 2003). The response patterns of the primary auditory cortex is modulated by task demands (attentional focus: Fritz 
et al., 2003; target properties: Fritz et al., 2005), attention, training effects (frequency discrimination: Recanzone et al., 1993), and predictive regularity in the auditory input (Winkler et al., 2009). Furthermore, early acoustic signal processing time for speech stimuli has been shown to be reduced with accompanying visual information, indicating that the primary auditory cortex activity is modulated by crossmodal input (Van Wassenhove et al., 2005). Thus, the primary auditory cortex is attuned to analyzing the details of the incoming acoustic signals, but is also influenced by contextual information and modulated by experience. Second, difficulty in resolving phonological categories would manifest in increased activity in the articulatory network. In contrast to the early spectrotemporal analyses of speech, later stages of phonological processing are largely insensitive to withincategory acoustic differences and exhibit enhanced sensitivity to across-category differences. Such phonological categorization is achieved via a complex network involving the inferior frontal cortex, insula, and the motor cortex (Myers et al., 2009; Lee et al., 2012; Chevillet et al., 2013).

Signal-to-phonology mapping, however, is not the only factor that modulates FAS perception. Listener beliefs regarding talker characteristics have been shown to modify the perceptual experience of speech (Campbell-Kibler, 2010; Drager, 2010). Specifically, different assumptions held about speaker properties by the individual listeners can potentially alter perception of the otherwise identical speech sounds. For instance, explicit talker labels (e.g., Canadian vs. Michigan) and indexical properties (e.g., gender, age, socioeconomic status) implied in visual representation of the talkers can change phonemic perception for otherwise identical speech sounds, even when the listeners are aware that this information is not accurate (Niedzielski, 1999; Strand, 1999; Hay et al., 2006a,b; Drager, 2011). The impact of perceived talker characteristics on FAS perception can be complex. Explicit labels have been linked to increased response times in lexical tasks for FAS, thus indicating increased processing load (Floccia et al., 2009), while visual presentation of race-matched faces have been shown to increase intelligibility for Chineseaccented speech (McGowan, 2011). These findings suggest that listener variability in FAS intelligibility may be partly accounted for using measures of listeners' susceptibility to these indexical cues (Hay et al., 2006b). In social psychology, the implicit association test (IAT) has been used extensively to quantify the degree of implicit bias which may not be measured using explicit self-reported questionnaire entries (Greenwald et al., 1998, 2009; Mcconnell and Leibold, 2001; Bertrand et al., 2005; Devos and Banaji, 2005; Kinoshita and Peek-O'leary, 2005). During an IAT, the participants are instructed to make associations between two sets of stimuli (e.g., American vs. Foreign scenes; Caucasian vs. Asian faces). The response times between two conditions (e.g., Caucasian-American and Asian-Foreign vs. Caucasian-Foreign and Asian-American) are compared, and the magnitude of the difference between the mean RTs are considered to reflect the degree of implicit bias toward the corresponding association. In non-speech research domains, the IAT measures have been shown to be positively correlated with neural responses to dispreferred stimuli in various networks, including the amygdala, prefrontal cortex, thalamus, striatum, and the anterior cingulate cortex
(Richeson et al., 2003; Krendl et al., 2006; Luo et al., 2006; Suslow et al., 2010). A recent study has shown that native American English listeners with greater implicit bias toward making Asianto-foreign and Caucasian-to-American associations experienced greater relative difficulties in transcribing English sentences in background noise, which were produced by native Korean speakers than that produced by native English speakers. This relationship between racial bias and FAS intelligibility was only observed when the auditory stimuli were paired with video recordings of the speakers producing the sentences (Figure 1; Yi et al., 2013). In spite of the novelty of the finding, did not reach a conclusive implication of the behavioral results, but rather cautiously suggesting that the listener bias likely led to altered incorporation of visual cues which are beneficial for enhancing speech intelligibility in adverse listening situations (Sumby and Pollack, 1954; Grant and Seitz, 2000). The precise neural mechanism underlying the relationship between listener bias and FAS perception remains unclear.

In this fMRI study, monolingual native English speakers $(N=$ 19) were presented with English sentences produced by native English or native Korean speakers in an MR scanner. The sentences were presented either along with video recordings of the speakers producing the sentences ("audiovisual modality") or without ("audio-only modality"). A rapid event-related design was used to acquire functional images. This setup allowed us to independently estimate BOLD responses to stimulus presentation and motor response on a trial-by-trial basis. Outside the scanner, the participants performed an IAT which was designed to measure the extent of the association between Asian faces and foreignness. Whole brain analyses were conducted to test the prediction that FAS perception would involve increased activation in the superior temporal cortex and the articulatory-phonological network, consistent with previous research on foreign phonemes processing (Golestani and Zatorre, 2004; Wilson and Iacoboni, 2006), speech intelligibility processing (Adank, 2012), and categorical perception in the inferior frontal gyrus (Myers et al., 2009; Rauschecker and Scott, 2009; Lee et al., 2012). ROI analyses were conducted to test whether the degree of implicit association between Asian faces and foreignness would be associated with modifications in the signal-to-phonology mapping process. For this purpose, the ROI analysis was restricted to the primary auditory cortex, involved in auditory input processing, and the inferior frontal gyrus, involved in phonological processing. Previous neuroimaging studies utilizing IAT as a covariate have consistently shown positive correlation between the IAT scores and the neural response to the dispreferred stimuli, which has led us to hypothesize that higher IAT scores (stronger Asian-Foreign and Caucasian-American association) would be associated with greater BOLD response to FAS, especially in the audiovisual modality.

\section{MATERIALS AND METHODS MATERIALS \\ Participants}

Nineteen young adults (age range: 18-35; 11 female) were recruited from the Austin community. All participants passed a hearing-screening exam (audiological thresholds $<25 \mathrm{~dB} \mathrm{HL}$ across octaves from 500 to $4000 \mathrm{~Hz}$ ), had normal or corrected 


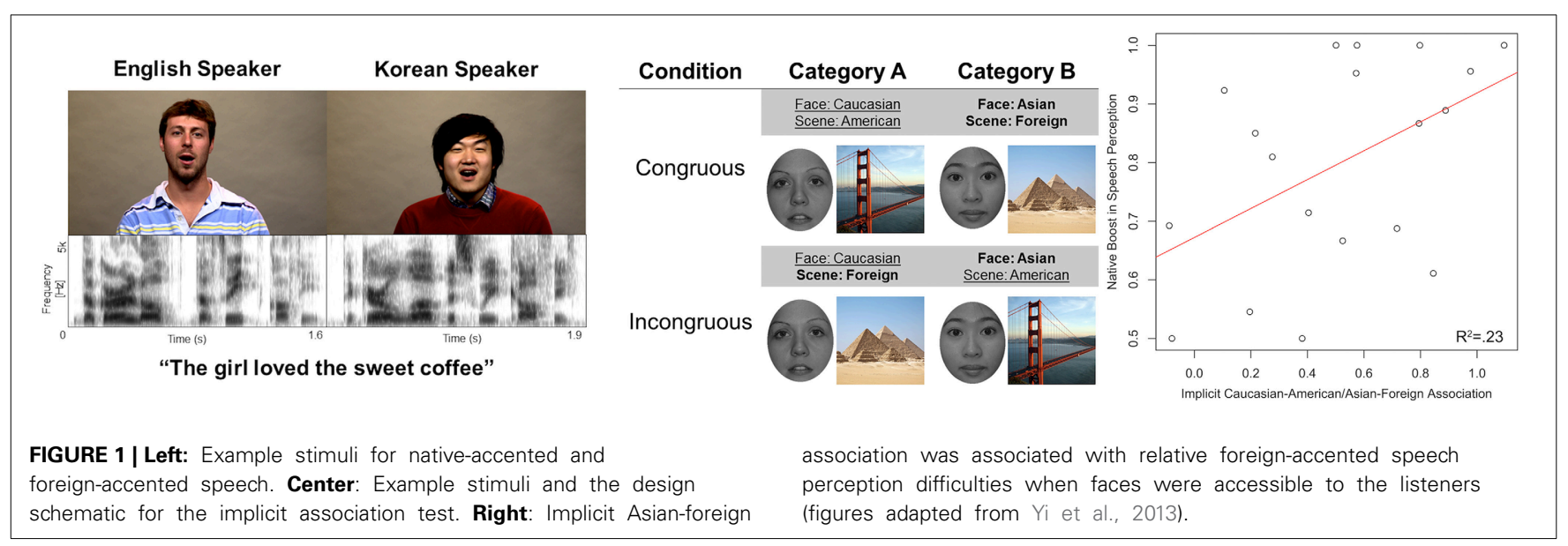

to normal vision, and self-reported to be right-handed. Potential participants were excluded if their responses to a standardized language history questionnaire revealed significant exposure to any language other than American English (LEAP-Q; Marian et al., 2007). Data from one participant (male) were excluded from all analysis due to detection of a structural anomaly. All recruitment and participation procedures were conducted in adherence to the University of Texas at Austin Institutional Review Board.

\section{Audiovisual speech stimuli}

Four native American English ( 2 female) and four native Korean speakers ( 2 female) produced 80 meaningful sentences with four keywords each (e.g., "the GIRL LOVED the SWEET COFFEE"; Calandruccio and Smiljanic, 2012). The speakers were between 18 and 35 years of age. The speakers were instructed to read text provided on the prompter as if they were talking to someone familiar with their voice and speech patterns. The NAS stimuli had been rated to be $96.2 \%$ native-like, and the FAS stimuli had been rated to be $20.7 \%$ native-like (converted from a 1-to9 Likert scale; Yi et al., 2013). Twenty non-overlapping sentences from each speaker was selected, resulting in 80 sentence stimuli used in the experiment. The video track was recorded using a Sony PMW-EX3 studio camera, and the audio track was recorded with an Audio Technica AT835b shotgun microphone placed on a floor stand in front of the speaker. Camera output was processed through a Ross crosspoint video switcher and recorded on an AJA Pro video recorder. The recording session was conducted on a sound-attenuated sound stage at The University of Texas at Austin. The raw video stream was exported using the following specifications. Codec: DV Video (dvsd); resolution: $720 \times 576$; frame rate: 29.969730 (Figure 1). The raw audio stream was RMS amplitude normalized to $62 \mathrm{~dB}$ SNL and exported using the following specifications. Codec: PCM S16 LE (araw); mono; sample rate: $48 \mathrm{kHz} ; 16$ bits per sample.

\section{IAT}

Ten young adult Asian (5 female) and 10 Caucasian (5 female) face images were used for Caucasian vs. Asian face categories (Minear and Park, 2004). All face images had been edited to exclude hair, face contour, ear, and neck information, then rendered into grayscale with constant luminosity (Goh et al., 2010). Public domain images of 10 iconic American scenes (Grand Canyon, Statue of Liberty, Wrigley Field, Golden Gate Bridge, Pentagon, Liberty Bell, White House, Capitol, New York Central Park, Empire State Building) and 10 non-American foreign scenes (Eiffel Tower, Pyramids, Angkor Wat, London Bridge, Brandenburg Gate, Stonehenge, Great Wall of China, Leaning Tower of Pisa, Sydney Opera House, Taj Mahal) were obtained online and used for American vs. Foreign scene categories. No scene image contained face information. All images were cropped to a square proportion. The stimuli and the design used for the IAT were identical to those used in our previous study (Figure 1; Yi et al., 2013).

\section{METHODS}

\section{Scan parameters}

The participants were scanned via the Siemens Magnetom Skyra 3T MRI scanner at the Imaging Research Center of the University of Texas at Austin. High-resolution whole-brain T1-weighted anatomical images were obtained via MPRAGE sequence $(T R=$ $2.53 \mathrm{~s} ; \mathrm{TE}=3.37 \mathrm{~ms} ; \mathrm{FOV}=25 \mathrm{~cm} ; 256 \times 256$ matrix; $1 \times 1 \mathrm{~mm}$ voxels; 176 axial slices; slice thickness $=1 \mathrm{~mm}$; distance factor $=$ $0 \%) .2^{*}$-weighted Whole-brain blood oxygen level dependent (BOLD) images were obtained using a gradient-echo multi-band EPI pulse sequence (flip angle $=60^{\circ} ; T R=1.8 \mathrm{~s} ; 166$ repetitions; $T E=30 \mathrm{~ms} ; \mathrm{FOV}=25 \mathrm{~cm} ; 128 \times 128$ matrix; $2 \times 2 \mathrm{~mm}$ voxels; 36 axial slices; slice thickness $=2 \mathrm{~mm}$; distance factor $=$ $50 \%$ ) using GRAPPA with an acceleration factor of 2 . Three hundred and thirty-four time points were collected, resulting in the scanning duration of approximately $10 \mathrm{~min}$. This was a part of a larger scanning protocol which lasted for approximately $1 \mathrm{~h}$ for each participant.

\section{fMRI task}

Participants were instructed to listen to the recorded sentences and rate the clarity of each one. After the presentation of each stimulus, a screen prompting the response was presented, upon which the participants rated the clarity of the stimulus by pressing one of the four buttons on the button boxes, ranging from 
1 (not clear) to 4 (very clear). This was done to ensure that participants were attending to the presentation of the stimuli. The audio track for the sentences were presented auditorily via MR-compatible insert earphones (ER30; Etymotic Research), and the visual track was presented via projector visible by an inscanner mirror. The stimuli were spoken by native English or native Korean speakers. There were two experimental conditions: an audio-only condition where only the acoustic signals were presented with a fixation cross being displayed, and an audiovisual condition where the video recordings of the talkers' faces producing the sentences were also presented. All sentences were presented only once in a single session without breaks. Therefore, the 80 sentences were subdivided into 20 sentences per each of the four conditions (native with visual cues; native without visual cues; nonnative with visual cues; nonnative without visual cues). We used a rapid event related design with jittered interstimulus intervals of 2-3 s. The order of the stimuli followed a pseudorandom sequence predetermined to avoid consecutive runs of stimuli of a given condition.

\section{IAT}

Following the fMRI acquisition session, IAT was conducted outside the scanner in a soundproof testing room. The IAT procedures were identical to those used in our previous study (Yi et al., 2013). For each trial, a face or scene stimulus was displayed on the screen. The face stimuli differed from the main task in the scanner in that they were still images unrelated to sentence production. In the congruous category condition, participants had to press a key on the keyboard when they saw a Caucasian face or an American scene, and a different key for an Asian face or a Foreign scene. In the incongruous category condition, participants had to press a key for a Caucasian face or a Foreign scene, and a different key for an Asian face or an American scene (Devos and Banaji, 2005). Participants were instructed to respond as quickly as possible without sacrificing accuracy. Each condition was presented twice with the key designations switched in a randomized order. These yielded four test blocks. Four practice blocks were included prior to the test blocks, in which only scenes or faces were presented. An incorrect response led to a corrective feedback of “Error!” (Greenwald et al., 2003).

\section{ANALYSES \\ IAT}

In a standalone analysis, a linear mixed effects analysis (Bates et al., 2012) was run with the response times in milliseconds as the dependent variable to directly quantify the delayed response times due to the incongruous association. The category condition (congruous vs. incongruous) and the neural index were entered as the fixed effects to measure the delay effect of face-scene pairings incongruent with the implicit association. By-subject random intercepts were included. The optimizer was set to BOBYQA (Powell, 2009). Individual IAT scores were calculated following the standard guidelines (Greenwald et al., 2003). Trials with response times longer than $10,000 \mathrm{~ms}$ or shorter than $400 \mathrm{~ms}$ were excluded. Response times for incorrect trials were replaced by the mean of the response times for correct trials within the same block, increased by $600 \mathrm{~ms}$. The average response time discrepancies across the two pairs of congruous vs. incongruous blocks were divided by the standard deviation of response times in the two blocks. These two discrepancy measures were averaged to yield in the final IAT score, which was used as a covariate in other analyses.

\section{Clarity rating}

Clarity ratings for all sentences from each participant were entered as the dependent variable, after being mean-centered to 0 , in a linear mixed effects analysis. In order to counteract different clarity criteria across the participants, the model was corrected for by-participant random intercepts. In the first analysis, the fixed effects included the accent and modality of the stimuli, the individual IAT measures, and the ensuing interactions. The optimizer was set to BOBYQA (Powell, 2009).

\section{fMRI preprocessing}

fMRI data were analyzed using FMRIB's Software Library Version 5.0 (Smith et al., 2004; Woolrich et al., 2009; Jenkinson et al., 2012). BOLD images were motion corrected using MCFLIRT (Jenkinson et al., 2002). All images were brain-extracted using BET (Smith, 2002; Jenkinson et al., 2005). Registration to the high-resolution anatomical image $(d f=6)$ and the MNI 152 template ( $d f=12$; Grabner et al., 2006a) was conducted using FLIRT (Jenkinson and Smith, 2001; Jenkinson et al., 2002). Six separate block-wise first-level analysis were run within-subject. The following pre-statistics processing were applied; spatial smoothing using a Gaussian kernel (FWHM $=5 \mathrm{~mm}$ ); grandmean intensity normalization of the entire $4 \mathrm{D}$ dataset by a single multiplicative factor; highpass temporal filtering (Gaussianweighted least-squares straight line fitting, with sigma $=50.0 \mathrm{~s}$ ). Each event was modeled as an impulse convolved with a canonical double-gamma hemodynamic response function ( phase $=0 \mathrm{~s}$ ). Motion estimates were modeled as nuisance covariates. Temporal derivative of each event regressor, including the motion estimates, was added. Time-series statistical analysis was carried out using FILM with local autocorrelation correction (Smith et al., 2004). The event regressors consisted of stimulus, response screen, and clarity response. The stimulus regressors were subdivided into accent (native vs. foreign) and modality (audiovisual vs. audioonly) conditions. The missed trials were separately estimated as nuisance variables. Three sets of $t$-test contrast pairs were tested, which examined modality (audiovisual - audio-only; audioonly - audiovisual), accent (native-accented - foreign-accented; foreign-accented - native-accented), and the interaction effects (audiovisual native - audiovisual foreign - audio-only native + audio-only foreign; audiovisual foreign - audiovisual native audio-only foreign + audio-only native).

\section{Whole brain analysis}

Group analysis was performed for each contrast using FLAME1 (Woolrich et al., 2009). To correct for multiple comparisons, post-statistical analysis was performed using randomize in FSL to run permutation tests $(n=50,000)$ for the GLM and yield in threshold-free cluster enhancement (TFCE) estimates of statistical significance. The corresponding family-wise error corrected p-values are presented in the results (Freedman and Lane, 1983; Kennedy, 1995; Bullmore et al., 1999; Anderson and Robinson, 
Table 1 | Whole brain analysis results for the contrasts of interest.

\begin{tabular}{|c|c|c|c|c|c|}
\hline Contrast & Regions & $\begin{array}{c}x \\
(\mathrm{~mm})\end{array}$ & $\begin{array}{c}y \\
(\mathrm{~mm})\end{array}$ & $\begin{array}{c}z \\
(\mathrm{~mm})\end{array}$ & Voxels \\
\hline \multicolumn{6}{|l|}{ MODALITY EFFECT } \\
\hline \multirow[t]{5}{*}{ (a) Audiovisual - audio-only } & $\begin{array}{l}\text { Bilateral occipital cortex; Bilateral fusiform } \\
\text { gyri; L posterior superior temporal gyrus; } \\
\text { Bilateral posterior middle temporal gyri }\end{array}$ & 38 & -46 & -22 & 14108 \\
\hline & $\mathrm{R}$ thalamus & 16 & -32 & 2 & 208 \\
\hline & $\mathrm{L}$ thalamus & -26 & -30 & -4 & 188 \\
\hline & R amygdala & 20 & -4 & -14 & 16 \\
\hline & R temporal pole & 56 & 6 & -22 & 13 \\
\hline \multirow[t]{6}{*}{ (b) Audio-only - audiovisual } & $\begin{array}{l}\text { R supeior parietal lobule; } \\
\text { R somatosensory cortex; } \\
\text { R supramarginal gyrus }\end{array}$ & 34 & -38 & 50 & 1864 \\
\hline & $\begin{array}{l}\text { R superior frontal gyrus; } \\
\text { R primary motor cortex }\end{array}$ & 24 & 4 & 64 & 804 \\
\hline & $\begin{array}{l}\text { L superior parietal lobule; } \\
\text { R somatosensory cortex }\end{array}$ & -38 & -36 & 42 & 330 \\
\hline & L middle frontal gyrus & -32 & 42 & 30 & 315 \\
\hline & L superior frontal gyrus & -26 & 4 & 56 & 177 \\
\hline & R middle frontal gyrus & 30 & 36 & 22 & 82 \\
\hline \multicolumn{6}{|l|}{ ACCENT EFFECT } \\
\hline (c) Native - foreign & $\begin{array}{l}\text { R posterior middle temporal gyrus; } \\
\text { R posterior inferior temporal gyrus; } \\
\text { R angular gyrus; R supramarginal gyrus }\end{array}$ & 64 & -46 & 26 & 379 \\
\hline \multirow[t]{8}{*}{ (d) Foreign - native } & Paracingulate gyrus & 4 & 24 & 34 & 904 \\
\hline & $\begin{array}{l}\text { R motor cortex, R superior parietal lobule; } \\
\text { R somatosensory cortex }\end{array}$ & 34 & -52 & 62 & 868 \\
\hline & $L$ insular cortex & -40 & 14 & 8 & 76 \\
\hline & R superior frontal gyrus & 20 & -2 & 60 & 68 \\
\hline & $\mathrm{R}$ insular cortex & 32 & 20 & -6 & 50 \\
\hline & L inferior frontal gyrus & -52 & 10 & 10 & 42 \\
\hline & $\mathrm{L}$ insular cortex & -26 & 24 & 0 & 31 \\
\hline & $\mathrm{R}$ insular cortex & 42 & 14 & 8 & 13 \\
\hline Modality by accent interaction & n.s. & & & & \\
\hline
\end{tabular}

Clusters are based on the $p<0.025$ threshold as well as the size criterion of 10 voxels.

2001; Nichols and Holmes, 2002; Hayasaka and Nichols, 2003). The results are presented in the Table 1.

\section{ROI analysis}

The ROIs were anatomically defined as the left and right primary auditory cortices (combination of Te 1.0, 1.1, and 1.2; Morosan et al., 2001) and the left inferior frontal gyrus (Brodmann area 44; Amunts et al., 1999) using the Jülich histological atlas (threshold $=$ 25\%; Eickhoff et al., 2005, 2006, 2007). Percent changes in BOLD responses for the stimuli in four conditions (native-accented with faces; native-accented without faces; foreign-accented with faces; foreign-accented without faces) were calculated by first linearly registering the ROIs to the individual BOLD spaces using FLIRT with the appropriate transformation matrices generated from the first level analysis and nearest neighbor interpolation (Jenkinson and Smith, 2001; Jenkinson et al., 2002). Then, the parameter estimate images were masked for the transformed ROIs, multiplied by height of the double gamma function for the stimulus length of $2 \mathrm{~s}$ (0.4075), converted into percent scale, divided by mean functional activation, and averaged within the ROI, using fslmaths (Mumford, 2007). The percent signal change was entered as the dependent variable in a linear mixed effects analysis. In the mixed effects analysis, the fixed effects included the accent (native vs. foreign), face (faces vs. no faces), individual IAT values and their interaction terms. The model was corrected for by-participant random intercepts (Bates et al., 2012). The optimizer was set to BOBYQA (Powell, 2009).

\section{RESULTS BEHAVIORAL RESULTS Clarity ratings}

The overall mean clarity rating was $2.94(S D=1.09)$. The mean clarity rating for the NAS was $3.28(S D=1.10)$ in the audioonly condition and $3.34(S D=1.06)$ in the audiovisual condition, while the rating for the FAS was $2.55(S D=0.96)$ in the audio-only condition and $2.57(S D=0.96)$ in the audiovisual 
condition. In this analysis, the fixed effects of modality, accent, the IAT scores, and their interaction terms were included as fixed effects for the dependent variable of clarity ratings for each sentence, which was mean-centered to 0 . The three-way interaction was not significant, which was excluded in the final model. The accent effect was significant, $b=-0.89, S E=0.095, t=-9.36$, $p<0.0001,95 \%$ CI $[-1.08,-0.70]$, indicating that FAS was perceived to be less clear than NAS. The accent by IAT interaction was significant, $b=0.33, S E=0.15, t=2.13, p=0.034,95 \%$ CI $[0.026,0.63]$, indicating that higher IAT values were more associated with higher perceived clarity ratings for the FAS relative to NAS. The intercept was significant, $b=0.97, S E=0.39$, $t=2.45, p=0.024,95 \%$ CI $[0.15,1.78]$. The modality effect was not significant, $b=-0.015, S E=0.094, t=-0.16, p=0.88$, 95\% CI $[-0.20,0.17]$, failing to provide evidence that perceived clarity was modified by the availability of visual cues. This is in contrast to the extensive previous literature that have indicated the intelligibility benefit from the audiovisual modality (Sumby and Pollack, 1954; Macleod and Summerfield, 1987; Ross et al., 2007). We ascribe this null finding to the task properties which did not require the participants to actively decipher the sentences, but only to rate their clarity (Munro and Derwing, 1995a). The IAT effect was not significant, $b=-0.34, S E=0.70$, $t=-0.49, p=0.63,95 \%$ CI $[-1.79,1.10]$. The modality by accent interaction was not significant, $b=-0.054, S E=0.077$, $t=-0.71, p=0.48,95 \%$ CI $[-0.20,0.096]$. The modality by IAT interaction was not significant, $b=0.15, S E=0.15, t=$ $0.97, p=0.33,95 \%$ CI $[-0.15,0.45]$. These results altogether suggest that FAS is perceived to be less clear by the listeners. Participants with higher IAT scores, i.e., those who were more likely to implicitly associate East Asian faces with foreignness, have decreased tendency to perceive FAS to be unclear, compared to NAS.

\section{IAT}

The overall mean response time was $948 \mathrm{~ms}(S D=586 \mathrm{~ms})$. The mean RT was $824 \mathrm{~ms}(S D=408 \mathrm{~ms})$ in the congruous condition, and $1073 \mathrm{~ms}(S D=700 \mathrm{~ms})$ in the incongruous condition. One fixed effects term was included in the model: incongruity of the stimuli pairing. The intercept was significant, $b=823.83, S E=$ 50.92, $t=19.50, p<0.0001,95 \%$ CI [718.84, 928.81], showing approximately $820 \mathrm{~ms}$ baseline response time. The incongruity effect was significant, $b=249.24, S E=19.90, t=12.52, p<$ $0.0001,95 \%$ CI $[210.22,288.27]$, suggesting that incongruous stimuli pairing delayed each response by approximately $250 \mathrm{~ms}$. The mean IAT score was calculated to be $0.51(S D=0.25)$, indicating a general trend of implicit bias toward making the Asian-Foreign association.

\section{fMRI RESULTS \\ Audio-only vs. Audiovisual}

BOLD signals were compared across the audiovisual and audioonly stimuli. The [audiovisual - audio-only] contrast revealed extensive activity in the occipital cortex, as the visual information in the faces required computations in the visual modality. Activity in the bilateral middle temporal gyri, left posterior superior temporal gyrus, and the right temporal pole was also observed, presumed to reflect integrative effort of the visual cues available in the facial stimuli (Sams et al., 1991; Möttönen et al., 2002; Pekkola et al., 2005). The [audio-only - audiovisual] contrast revealed activity in the bilateral superior and middle frontal gyri, right motor and somatosensory cortices, and the bilateral supramarginal gyri (Figure 2). The increased activation in the motor and somatosensory areas for audio-only speech than for audiovisual speech is in contrast to previous research that has shown the opposite pattern (Skipper et al., 2005). It is possible that the absence of visual cues induced more effortful processing in these areas. The activity in these regions is presumed to reflect the necessity of additional computation in the speech processing network.

\section{Native- vs. Foreign-accented speech}

BOLD signals were compared across the speaker accent. The [native - foreign] contrast revealed greater activity in the right angular gyrus, supramarginal gyrus, the posterior middle, and inferior temporal gyri. Supramarginal gyri have been suggested to be involved in making phonological decisions, which in the context of this study is presumed to reflect improved phonological

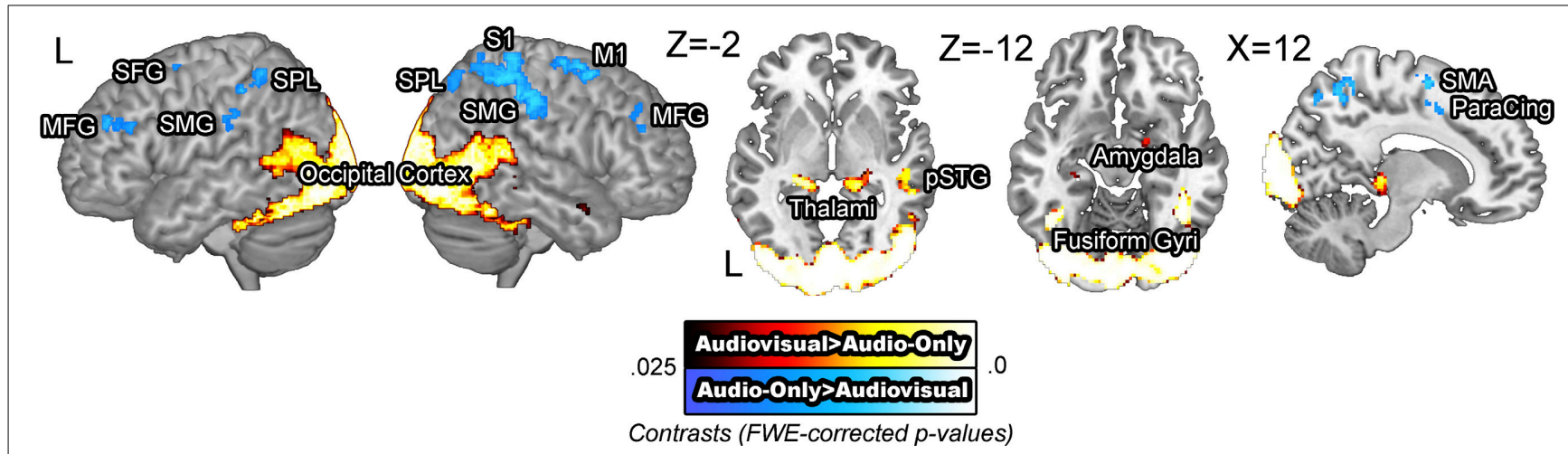

FIGURE 2 | BOLD signals in the audio-only vs. audiovisual comparison. The [audiovisual - audio-only] contrast revealed extensive activity in the occipital cortex and the bilateral posterior middle temporal gyri. The [audio-only - audiovisual] contrast revealed activity in the right middle frontal gyrus, right motor and somatosensory areas and the superior parietal lobule. 


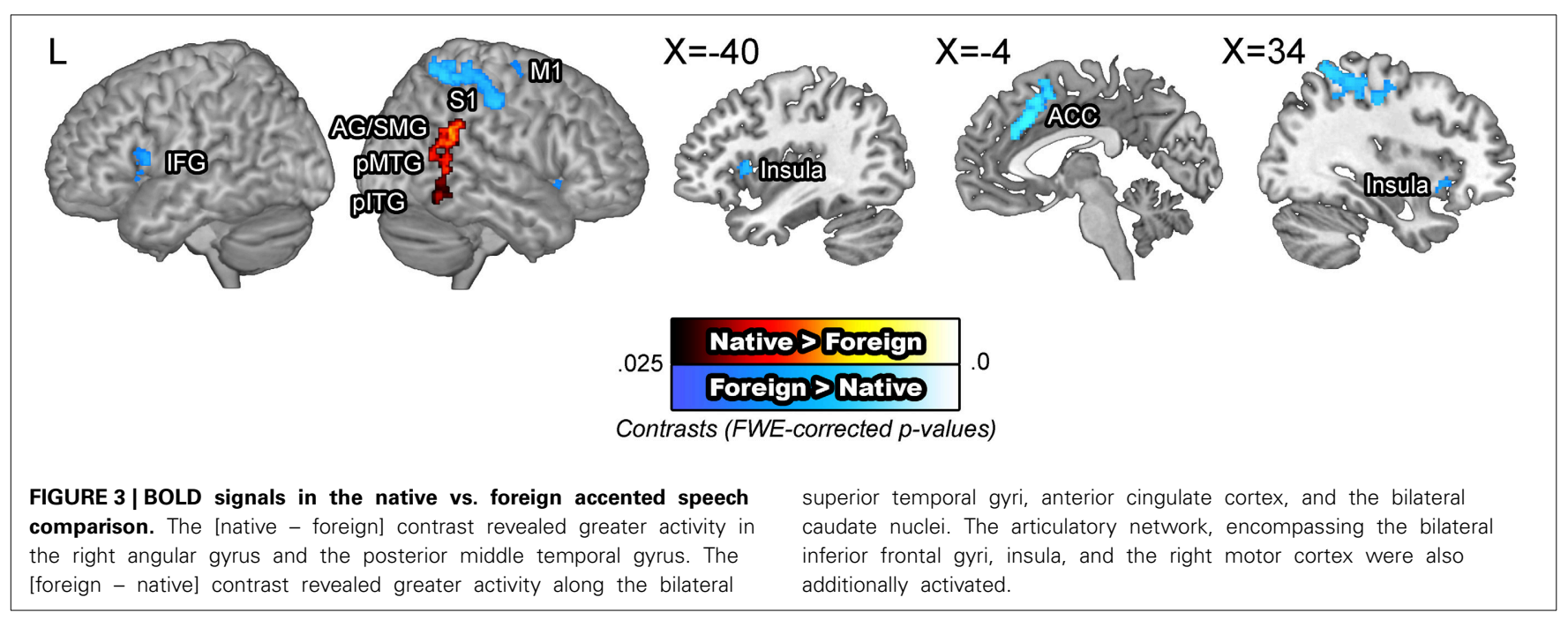

processing for NAS than for FAS (Hartwigsen et al., 2010). The [foreign - native] contrast revealed greater activity in the motor cortex, somatosensory cortex, inferior frontal gyrus, insula, and the anterior cingulate cortex. These areas have been previously indicated to be additionally recruited for perception of foreign phonemes (Golestani and Zatorre, 2004; Wilson and Iacoboni, 2006) or distorted speech (Adank, 2012). The omission of the superior temporal areas are significant, which run counter to our initial hypothesis regarding increased computational demand due to unfamiliar auditory input. A potential interpretation of this null finding is that the activity in the superior temporal cortex was more variable than that in the motor and frontal areas, an idea which was tested in the subsequent ROI analysis (Figure 3). The modality by accent interaction contrasts did not yield significant results.

\section{ROI analyses}

The ROI analyses were constrained to the left and right primary auditory cortices and the left inferior frontal gyrus. The fixed effects included accent (foreign- vs. native-accented speech), modality (audiovisual vs. audio-only), IAT scores, and their interaction terms. In the left primary auditory cortex, no threeway or two-way interactions were significant, leaving the model with only three main effects of accent, modality and IAT to be considered. The modality effect was significant, $b=-0.047$, $S E=0.014, t=-3.34, p=0.0016,95 \%$ CI $[-0.075,-0.020]$, suggesting that the audiovisual stimuli reduced computational demand in this region, relative to the audio-only stimuli. The accent effect was not significant, $b=0.010, S E=0.014, t=0.71$, $p=0.48,95 \%$ CI $[-0.018,0.038]$. The IAT effect was not significant, $b=-0.27, S E=0.20, t=-1.31, p=0.21,95 \% \mathrm{CI}$ $[-0.66,0.13]$. The intercept was significant, $b=0.45, S E=0.11$, $t=3.89, p=0.0013,95 \%$ CI $[0.22,0.67]$. In the right primary auditory cortex, the three-way interaction across modality, accent, and IAT was significant, $b=0.25, S E=0.11, t=2.26$, $p=0.028,95 \%$ CI $[0.042,0.46]$, suggesting that higher IAT scores were associated with increased response to FAS with faces (Figure 4). The interaction between accent and modality was
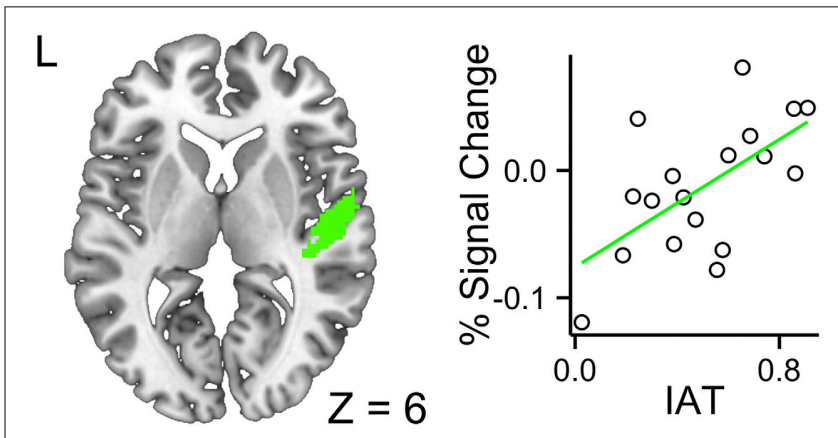

FIGURE 4 | Higher a given participant's IAT score, greater the BOLD response for the interaction contrast between foreign-accented speech and the availability of faces in the right primary auditory cortex. This indicated that participants with higher IAT scores required additional processing resources for foreign-accented speech with faces.

significant, $b=-0.15, S E=0.062, t=-2.43, p=0.019,95 \%$ CI $[-0.27,-0.34]$, suggesting that the decreased neural efficiency due to FAS was ameliorated by the availability of faces. The accent effect was significant, $b=0.090, S E=0.044, t=$ $2.04, p=0.047,95 \%$ CI $[0.0070,0.17]$, suggesting that FAS increased the computational demand in this region. The intercept was significant, $b=0.32, S E=0.12, t=2.57, p=0.020$, $95 \%$ CI $[0.077,0.55]$. The accent by IAT interaction was not significant, $b=-0.061, S E=0.078, t=-0.78, p=0.44,95 \% \mathrm{CI}$ $[-0.21,0.087]$. The IAT by modality interaction was not significant, $b=-0.13, S E=0.078, t=-1.65, p=0.11,95 \% \mathrm{CI}$ $[-0.28,0.018]$. The modality by accent interaction was not significant, $b=-0.15, S E=0.062, t=-2.43, p=0.019,95 \% \mathrm{CI}$ $[-0.27,-0.034]$. The IAT main effect was not significant, $b=$ $-0.23, S E=0.22, t=-1.03, p=0.32,95 \%$ CI $[-0.65,0.20]$. The modality main effect was not significant, $b=0.011, S E=$ $0.044, t=0.25, p=0.81,95 \%$ CI $[-0.072,0.094]$. The intercept was significant, $b=0.32, S E=0.12, t=2.57, p=0.020,95 \% \mathrm{CI}$ $[0.077,0.55]$. 
In the left inferior frontal gyrus, no three-way or two-way interactions were significant, leaving the model with only three main effects of accent, modality and IAT to be considered. The accent effect was significant, $b=0.058, S E=0.018, t=$ $3.15, p=0.0028,95 \%$ CI $[0.022,0.094]$, suggesting that FAS increased computational demand in this region. The IAT effect was not significant, $b=-0.37, S E=0.20, t=-1.83, p=0.086$, 95\% CI $[-0.76,0.024]$. The modality effect was not significant, $b=-0.026, S E=0.018, t=-1.41, p=0.16,95 \%$ CI $[-0.062$, $0.010]$. The intercept was not significant, $b=0.12, S E=0.11$, $t=1.02, p=0.32,95 \%$ CI $[-0.11,0.34]$. In the right inferior frontal gyrus, no three-way or two-way interactions were significant, leaving the model with only three main effects of accent, modality, and IAT to be considered, The accent effect was not significant, $b=0.0080, S E=0.019, t=0.43, p=0.67,95 \% \mathrm{CI}$ $[-0.029,0.045]$. The IAT effect was not significant, $b=-0.36$, $S E=0.19, t=-1.89, p=0.077,95 \%$ CI $[-0.74,0.011]$. The modality effect was not significant, $b=-0.0090, S E=0.019$, $t=-0.48, p=0.63,95 \%$ CI $[-0.046,0.028]$. The intercept was not significant, $b=0.12, S E=0.11, t=1.10, p=0.29,95 \% \mathrm{CI}$ $[-0.093,0.33]$.

\section{DISCUSSION}

Listening to FAS can be challenging compared to NAS. This difficulty can be partly attributed to a demanding process of mapping somewhat unreliable incoming signals to phonology. We hypothesized that FAS perception will require additional spectrotemporal analysis of the acoustic signal and place a greater demand on the phonological processing network. We therefore predicted increased functional activity in the superior temporal cortex and the inferior frontal gyrus, insula, and the motor cortex (Hickok and Poeppel, 2007; Rauschecker and Scott, 2009; Adank and Devlin, 2010; Adank et al., 2012a,b). Furthermore, FAS perception is additionally modulated by listeners' underlying implicit bias (Greenwald et al., 1998, 2009; Mcconnell and Leibold, 2001; Bertrand et al., 2005; Devos and Banaji, 2005; Kinoshita and Peek-O'leary, 2005; Yi et al., 2013). Thus, we hypothesized that individual variability in implicit Asian-foreign association will be associated with functional activity during early spectrotemporal analysis in the primary auditory cortex or for later, more categorical processing in the inferior frontal gyrus (Hickok and Poeppel, 2007; Rauschecker and Scott, 2009).

\section{INCREASED COMPUTATIONAL DEMAND FOR FOREIGN-ACCENTED SPEECH PROCESSING}

Relative to native speech, FAS was associated with increased BOLD response in the bilateral superior temporal cortices, potentially reflecting increased computational demand on these regions. The anterior and posterior portions of the superior temporal cortex have been associated with spectrotemporal analysis of the speech signal (Hickok and Poeppel, 2007), as well as with speech intelligibility processing (Scott et al., 2000; Narain et al., 2003; Okada et al., 2010; Abrams et al., 2013). While these previous studies have observed increased activation of the superior temporal cortex for intelligible speech compared to unintelligible acoustically complex stimuli, we found increased activation for the FAS stimuli than for the NAS stimuli, although FAS is less intelligible than NAS (Yi et al., 2013). This contradiction is resolved by considering the nature of comparisons involved in previous neuroimaging studies examining mechanisms underlying speech intelligibility. Both native- and FAS used in the current study have semantic and syntactic content which are absent in non-speech stimuli used as control in the previous studies (e.g., spectrally-rotated speech), and both functions have been suggested to occur within the superior temporal cortex (Friederici et al., 2003). The superior temporal cortex is a large region with possibly multiple functional roles in processing information in the speech signal. A direct recording study has shown that speech sound categorization is represented in the posterior superior temporal cortex (Chang et al., 2010), while a direct stimulation study had indicated the role of anterior superior temporal cortex in comprehension but not auditory perception (Matsumoto et al., 2011).

We found that presentation of FAS was associated with greater activity in the articulatory-phonological network, encompassing bilateral inferior frontal gyri, insula, and the right motor cortex. The inferior frontal gyrus is thought to be responsible for mapping auditory signals onto articulatory gestures (Myers et al., 2009; Lee et al., 2012; Chevillet et al., 2013). It has been suggested that the role of the inferior frontal gyrus is defined by the linkage between motor observation and imitation, which allows for abstraction of articulatory gestures from the auditory signals, along with the motor cortex and the insula (Ackermann and Riecker, 2004, 2010; Molnar-Szakacs et al., 2005; Pulvermüller, 2005; Pulvermüller et al., 2005, 2006; Skipper et al., 2005; Galantucci et al., 2006; Meister et al., 2007; Iacoboni, 2008; Kilner et al., 2009; Pulvermüller and Fadiga, 2010). On the other hand, both fMRI and transcranial magnetic stimulation (TMS) studies have indicated a functional heterogeneity within the inferior frontal cortex, which includes semantic processing (Homae et al., 2002; Devlin et al., 2003; Gough et al., 2005). The FAS and NAS stimuli had been controlled for syntactic, semantic, and phonological complexity (Calandruccio and Smiljanic, 2012). Since the task for each stimulus had also been identical (clarity rating), the increased activation across the speech processing network-including the superior temporal cortex and the articulatory network-during FAS perception is interpreted to reflect decreased neural efficiency for FAS processing (Grabner et al., 2006b; Rypma et al., 2006; Neubauer and Fink, 2009).

\section{IMPLICIT ASIAN-FOREIGN ASSOCIATION ASSOCIATED WITH EARLY SPECTROTEMPORAL ANALYSIS}

Previous behavioral studies have shown that FAS perception is modulated not only by the signal-driven factors, but also by the listener-driven factors. These listener factors can include listeners' familiarity and experience with the talkers (Bradlow and Pisoni, 1999) or language experience (Bradlow and Pisoni, 1999; Bent and Bradlow, 2003). Multiple studies have shown that listeners are also sensitive to the information regarding talker properties (Campbell-Kibler, 2010; Drager, 2010), either through explicit labels (Niedzielski, 1999; Hay et al., 2006a; Floccia et al., 2009) or facial cues (Strand, 1999; Hay et al., 2006b; Drager, 2011; McGowan, 2011; Yi et al., 2013). Listeners vary in their susceptibility to these talker cues (Hay et al., 2006b), which can override 
their explicit knowledge (Hay et al., 2006a). Accordingly, listeners' implicit association between faces and foreignness (Greenwald et al., 1998, 2009; Mcconnell and Leibold, 2001; Bertrand et al., 2005; Devos and Banaji, 2005; Kinoshita and Peek-O'leary, 2005) modulates FAS perception only when the faces are present, through a neural mechanism hitherto unknown (Yi et al., 2013). In this study, the IAT was used to measure the degree of listener bias in which the East Asian faces are associated with foreignness of the speakers (Greenwald et al., 1998, 2009; Mcconnell and Leibold, 2001; Bertrand et al., 2005; Devos and Banaji, 2005; Kinoshita and Peek-O'leary, 2005). Previous fMRI studies that have used IAT as a covariate have consistently showed a pattern in which higher measures of implicit association are associated with higher activation in various neural areas for dispreferred stimuli (Richeson et al., 2003; Krendl et al., 2006; Luo et al., 2006; Suslow et al., 2010).

Examining the connection between FAS perception and listener bias, we found that listeners' implicit Asian-foreign association was reflected in the functional activity in the right primary auditory cortex. Participants with higher IAT scores showed greater activity in the primary auditory cortex for Koreanaccented sentences when audiovisual information was presented. The primary auditory cortex is the site for early spectrotemporal analysis for the speech signal, sensitive to acoustic properties of the signal (Strainer et al., 1997), as well as task demands (Fritz et al., 2003, 2005), attention (Jäncke et al., 1999), context (Javit et al., 1994), and training effects (Recanzone et al., 1993). In contrast, IAT scores were not associated with the activity in the inferior frontal gyrus. Past findings indicated that individual listeners' perceived talker properties from pictorial stimuli differentially modulate the perceptual experience (Hay et al., 2006b). In the case of FAS, the presentation of race-matched faces enhanced perception of Chinese-accented English speech (McGowan, 2011), and the individual variability in implicit Asian-foreign association predicted Korean-accented speech intelligibility (Yi et al., 2013). The present findings suggest that the listeners' implicit bias for associating Asian speakers with foreignness may be related to the early neural processing for FAS, specifically low-level spectrotemporal analysis of the acoustic properties of the signal.

\section{LIMITATIONS AND FUTURE DIRECTIONS}

In this study, Korean-accented speech was used as the proxy for FAS. Accordingly, all foreign-accented talkers appeared East Asian. In order to extend our results to the general phenomenon of FAS perception, we propose a multifactorial design in future studies where, in addition to the stimuli produced by Caucasian native speakers and Asian nonnative speakers, those by Asian native speakers and Caucasian nonnative speakers are incorporated into the study design. Also, additional explicit questionnaire on listener experience and exposure to foreign-accented stimuli could be collected to augment our understanding of the complex nature in which underlying listener biases modulate speech perception. Finally, we acknowledge that the current study did not incorporate parametric variations on the intelligibility or accentedness of the FAS stimuli. Therefore, it is impossible to determine whether the increased BOLD response in the speech processing areas and the anterior cingulate cortex reflects increased difficulty in comprehension or the degree of perceived foreign accent per se (Peelle et al., 2004; Wong et al., 2008).

\section{CONCLUSIONS}

In this study, we presented evidence of increased computational demand for FAS perception. Changes in the reduced neural efficiency for FAS processing was associated with the variability in the underlying listener biases (Yi et al., 2013). These results suggest that implicit racial association is associated with early neural response to FAS. Future studies on speech perception should examine the contribution of visual cues and listener implicit biases in order to obtain a more comprehensive understanding of the phenomenon of FAS processing.

\section{ACKNOWLEDGMENTS}

Research reported in this publication was supported by the National Institute On Deafness And Other Communication Disorders of the National Institutes of Health under Award Number R01DC013315 awarded to Bharath Chandrasekaran as well as the Longhorn Innovation Fund for Technology to Bharath Chandrasekaran and Rajka Smiljanic. The authors thank Kirsten Smayda, Jasmine E. B. Phelps, and Rachael Gilbert for significant contributions in data collection and processing; the faculty and the staff of the Imaging Research Center at the University of Texas at Austin for technical support and counsel; the Texas Advanced Computing Center at The University of Texas at Austin for providing computing resources.

\section{REFERENCES}

Abrams, D. A., Ryali, S., Chen, T., Balaban, E., Levitin, D. J., and Menon, V. (2013). Multivariate activation and connectivity patterns discriminate speech intelligibility in Wernicke's, Broca's, and Geschwind's Areas. Cereb. Cortex 23, 1703-1714. doi: 10.1093/cercor/bhs165

Ackermann, H., and Riecker, A. (2004). The contribution of the insula to motor aspects of speech production: a review and a hypothesis. Brain Lang. 89, 320-328. doi: 10.1016/S0093-934X(03)00347-X

Ackermann, H., and Riecker, A. (2010). The contribution (s) of the insula to speech production: a review of the clinical and functional imaging literature. Brain Struct. Funct. 214, 419-433. doi: 10.1007/s00429-010-0257-x

Adank, P. (2012). The neural bases of difficult speech comprehension and speech production: two activation likelihood estimation (ALE) meta-analyses. Brain Lang. 122, 42-54. doi: 10.1016/j.bandl.2012.04.014

Adank, P., Davis, M. H., and Hagoort, P. (2012a). Neural dissociation in processing noise and accent in spoken language comprehension. Neuropsychologia 50 , 77-84. doi: 10.1016/j.neuropsychologia.2011.10.024

Adank, P., Noordzij, M. L., and Hagoort, P. (2012b). The role of planum temporale in processing accent variation in spoken language comprehension. Hum. Brain Mapp. 33, 360-372. doi: 10.1002/hbm.21218

Adank, P., and Devlin, J. T. (2010). On-line plasticity in spoken sentence comprehension: adapting to time-compressed speech. Neuroimage 49, 1124-1132. doi: 10.1016/j.neuroimage.2009.07.032

Amunts, K., Schleicher, A., Bürgel, U., Mohlberg, H., Uylings, H., and Zilles, K. (1999). Broca's region revisited: cytoarchitecture and intersubject variability. J. Comp. Neurol. 412, 319-341.

Anderson-Hsieh, J., Johnson, R., and Koehler, K. (1992). The relationship between native speaker judgments of nonnative pronunciation and deviance in segmentais, prosody, and syllable structure. Lang. Learn. 42, 529-555. doi: 10.1111/j.1467-1770.1992.tb01043.x

Anderson-Hsieh, J., and Koehler, K. (1988). The effect of foreign accent and speaking rate on native speaker comprehension*. Lang. Learn. 38, 561-613. doi: 10.1111/j.1467-1770.1988.tb00167.x

Anderson, M. J., and Robinson, J. (2001). Permutation tests for linear models. Aust. N.Z. J. Stat. 43, 75-88. doi: 10.1111/1467-842X.00156 
Baese-Berk, M. M., Bradlow, A. R., and Wright, B. A. (2013). Accent-independent adaptation to foreign accented speech. J. Acoust. Soc. Am. 133, EL174-EL180. doi: 10.1121/1.4789864

Bates, D., Maechler, M., and Bolker, B. (2012). lme4: Linear Mixed-Effects Models Using S4 Classes. Available online at: http://CRAN.R-project.org/package=lme 4

Bent, T., and Bradlow, A. R. (2003). The interlanguage speech intelligibility benefit. J. Acoust. Soc. Am. 114, 1600-1610. doi: 10.1121/1.1603234

Bertrand, M., Chugh, D., and Mullainathan, S. (2005). Implicit discrimination. Am. Econ. Rev. 94-98. doi: 10.1257/000282805774670365

Bradlow, A. R., and Bent, T. (2008). Perceptual adaptation to non-native speech. Cognition 106, 707-729. doi: 10.1016/j.cognition.2007.04.005

Bradlow, A. R., and Pisoni, D. B. (1999). Recognition of spoken words by native and non-native listeners: talker-, listener-, and item-related factors. J. Acoust. Soc. Am. 106, 2074-2085. doi: 10.1121/1.427952

Bullmore, E. T., Suckling, J., Overmeyer, S., Rabe-Hesketh, S., Taylor, E., and Brammer, M. J. (1999). Global, voxel, and cluster tests, by theory and permutation, for a difference between two groups of structural MR images of the brain. IEEE Trans. Med. Imaging 18, 32-42. doi: 10.1109/42.750253

Calandruccio, L., and Smiljanic, R. (2012). New sentence recognition materials developed using a basic non-native english lexicon. J. Speech Lang. Hear. Res. 55, 1342-1355. doi: 10.1044/1092-4388(2012/11-0260)

Campbell-Kibler, K. (2010). Sociolinguistics and perception. Lang. Linguist. Compass 4, 377-389. doi: 10.1111/j.1749-818X.2010.00201.x

Chang, E. F., Rieger, J. W., Johnson, K., Berger, M. S., Barbaro, N. M., and Knight, R. T. (2010). Categorical speech representation in human superior temporal gyrus. Nat. Neurosci. 13, 1428-1432. doi: 10.1038/nn.2641

Chevillet, M. A., Jiang, X., Rauschecker, J. P., and Riesenhuber, M. (2013). Automatic phoneme category selectivity in the dorsal auditory stream. J. Neurosci. 33, 5208-5215. doi: 10.1523/JNEUROSCI.1870-12.2013

Clarke, C. M., and Garrett, M. F. (2004). Rapid adaptation to foreign-accented English. J. Acoust. Soc. Am. 116, 3647-3658. doi: 10.1121/1.1815131

Devlin, J. T., Matthews, P. M., and Rushworth, M. F. (2003). Semantic processing in the left inferior prefrontal cortex: a combined functional magnetic resonance imaging and transcranial magnetic stimulation study. J. Cogn. Neurosci. 15, 71-84. doi: 10.1162/089892903321107837

Devos, T., and Banaji, M. R. (2005). American= white? J. Pers. Soc. Psychol. 88:447. doi: 10.1037/0022-3514.88.3.447

Drager, K. (2010). Sociophonetic variation in speech perception. Lang. Linguist. Compass 4, 473-480. doi: 10.1111/j.1749-818X.2010.00210.x

Drager, K. (2011). Speaker age and vowel perception. Lang. Speech 54, 99-121. doi: $10.1177 / 0023830910388017$

Eickhoff, S. B., Heim, S., Zilles, K., and Amunts, K. (2006). Testing anatomically specified hypotheses in functional imaging using cytoarchitectonic maps Neuroimage 32, 570-582. doi: 10.1016/j.neuroimage.2006.04.204

Eickhoff, S. B., Paus, T., Caspers, S., Grosbras, M.-H., Evans, A. C., Zilles, K., et al. (2007). Assignment of functional activations to probabilistic cytoarchitectonic areas revisited. Neuroimage 36, 511-521. doi: 10.1016/j.neuroimage.2007.03.060

Eickhoff, S. B., Stephan, K. E., Mohlberg, H., Grefkes, C., Fink, G. R., Amunts, K., et al. (2005). A new SPM toolbox for combining probabilistic cytoarchitectonic maps and functional imaging data. Neuroimage 25, 1325-1335. doi: 10.1016/j.neuroimage.2004.12.034

Floccia, C., Butler, J., Goslin, J., and Ellis, L. (2009). Regional and foreign accent processing in English: can listeners adapt? J. Psycholinguist. Res. 38, 379-412. doi: 10.1007/s10936-008-9097-8

Freedman, D., and Lane, D. (1983). A nonstochastic interpretation of reported significance levels. J. Bus. Econ. Stat. 1, 292-298.

Friederici, A. D., Rüschemeyer, S.-A., Hahne, A., and Fiebach, C. J. (2003). The role of left inferior frontal and superior temporal cortex in sentence comprehension: localizing syntactic and semantic processes. Cereb. Cortex 13, 170-177. doi: 10.1093/cercor/13.2.170

Fritz, J., Elhilali, M., and Shamma, S. (2005). Active listening: task-dependent plasticity of spectrotemporal receptive fields in primary auditory cortex. Hear. Res. 206, 159-176. doi: 10.1016/j.heares.2005.01.015

Fritz, J., Shamma, S., Elhilali, M., and Klein, D. (2003). Rapid task-related plasticity of spectrotemporal receptive fields in primary auditory cortex. Nat. Neurosci. 6 , 1216-1223. doi: 10.1038/nn1141

Galantucci, B., Fowler, C. A., and Turvey, M. T. (2006). The motor theory of speech perception reviewed. Psychon. Bull. Rev. 13, 361-377. doi: 10.3758/BF031 93857
Goh, J. O., Suzuki, A., and Park, D. C. (2010). Reduced neural selectivity increases fMRI adaptation with age during face discrimination. Neuroimage 51, 336-344. doi: 10.1016/j.neuroimage.2010.01.107

Golestani, N., and Zatorre, R. J. (2004). Learning new sounds of speech: reallocation of neural substrates. Neuroimage 21, 494-506. doi: 10.1016/j.neuroimage.2003.09.071

Gough, P. M., Nobre, A. C., and Devlin, J. T. (2005). Dissociating linguistic processes in the left inferior frontal cortex with transcranial magnetic stimulation. J. Neurosci. 25, 8010-8016. doi: 10.1523/JNEUROSCI.2307-05.2005

Grabner, G., Janke, A. L., Budge, M. M., Smith, D., Pruessner, J., and Collins, D. L. (2006a). "Symmetric atlasing and model based segmentation: an application to the hippocampus in older adults," in Medical Image Computing and ComputerAssisted Intervention-MICCAI 2006, eds R. Larsen, M. Nielsen, and J. Sporring (Berlin: Springer), 58-66. doi: 10.1007/11866763_8

Grabner, R. H., Neubauer, A. C., and Stern, E. (2006b). Superior performance and neural efficiency: the impact of intelligence and expertise. Brain Res. Bull. 69, 422-439. doi: 10.1016/j.brainresbull.2006.02.009

Grant, K. W., and Seitz, P.-F. (2000). The use of visible speech cues for improving auditory detection of spoken sentences. J. Acoust. Soc. Am. 108, 1197-1208. doi: $10.1121 / 1.1288668$

Greenwald, A. G., McGhee, D. E., and Schwartz, J. L. (1998). Measuring individual differences in implicit cognition: the implicit association test. J. Pers. Soc. Psychol. 74:1464. doi: 10.1037/0022-3514.74.6.1464

Greenwald, A. G., Nosek, B. A., and Banaji, M. R. (2003). Understanding and using the implicit association test: I. An improved scoring algorithm. J. Pers. Soc Psychol. 85:197. doi: 10.1037/0022-3514.85.2.197

Greenwald, A. G., Poehlman, T. A., Uhlmann, E. L., and Banaji, M. R. (2009) Understanding and using the Implicit Association Test: III. Meta-analysis of predictive validity. J. Pers. Soc. Psychol. 97, 17. doi: 10.1037/a0015575

Hartwigsen, G., Baumgaertner, A., Price, C. J., Koehnke, M., Ulmer, S., and Siebner, H. R. (2010). Phonological decisions require both the left and right supramarginal gyri. Proc. Natl. Acad. Sci. U.S.A. 107, 16494-16499. doi: 10.1073/pnas.1008121107

Hay, J., Nolan, A., and Drager, K. (2006a). From fush to feesh: exemplar priming in speech perception. Linguist. Rev. 23, 351-379. doi: 10.1515/TLR.2006.014

Hay, J., Warren, P., and Drager, K. (2006b). Factors influencing speech perception in the context of a merger-in-progress. J. Phon. 34, 458-484. doi: 10.1016/j.wocn.2005.10.001

Hayasaka, S., and Nichols, T. E. (2003). Validating cluster size inference: random field and permutation methods. Neuroimage 20, 2343-2356. doi: 10.1016/j.neuroimage.2003.08.003

Hickok, G., and Poeppel, D. (2007). The cortical organization of speech processing. Nat. Rev. Neurosci. 8, 393-402. doi: 10.1038/nrn2113

Homae, F., Hashimoto, R., Nakajima, K., Miyashita, Y., and Sakai, K. L. (2002). From perception to sentence comprehension: the convergence of auditory and visual information of language in the left inferior frontal cortex. Neuroimage 16, 883-900. doi: 10.1006/nimg.2002.1138

Iacoboni, M. (2008). The role of premotor cortex in speech perception: evidence from fMRI and rTMS. J. Physiol. Paris 102, 31-34. doi: 10.1016/j.jphysparis.2008.03.003

Jäncke, L., Mirzazade, S., and Joni Shah, N. (1999). Attention modulates activity in the primary and the secondary auditory cortex: a functional magnetic resonance imaging study in human subjects. Neurosci. Lett. 266, 125-128. doi: 10.1016/S0304-3940(99)00288-8

Javit, D. C., Steinschneider, M., Schroeder, C. E., Vaughan, H. G. Jr., and Arezzo, J. C. (1994). Detection of stimulus deviance within primate primary auditory cortex: intracortical mechanisms of mismatch negativity (MMN) generation. Brain Res. 667, 192-200. doi: 10.1016/0006-8993(94)91496-6

Jenkinson, M., Bannister, P., Brady, M., and Smith, S. (2002). Improved optimization for the robust and accurate linear registration and motion correction of brain images. Neuroimage 17, 825-841. doi: 10.1006/nimg.2002.1132

Jenkinson, M., Beckmann, C. F., Behrens, T. E., Woolrich, M. W., and Smith, S. M. (2012). Fsl. Neuroimage 62, 782-790. doi: 10.1016/j.neuroimage.2011.09.015

Jenkinson, M., Pechaud, M., and Smith, S. (2005). "BET2: MR-based estimation of brain, skull and scalp surfaces," in Eleventh Annual Meeting of the Organization for Human Brain Mapping (Toronto, ON).

Jenkinson, M., and Smith, S. (2001). A global optimisation method for robust affine registration of brain images. Med. Image Anal. 5, 143-156. doi: 10.1016/S13618415(01)00036-6 
Kennedy, F. E. (1995). Randomization tests in econometrics. J. Bus. Econ. Stat. 13, 85-94.

Kilner, J. M., Neal, A., Weiskopf, N., Friston, K. J., and Frith, C. D. (2009). Evidence of mirror neurons in human inferior frontal gyrus. J. Neurosci. 29, 10153-10159. doi: 10.1523/JNEUROSCI.2668-09.2009

Kinoshita, S., and Peek-O'leary, M. (2005). Does the compatibility effect in the race Implicit Association Test reflect familiarity or affect? Psychon. Bull. Rev. 12, 442-452. doi: 10.3758/BF03193786

Krendl, A. C., Macrae, C. N., Kelley, W. M., Fugelsang, J. A., and Heatherton, T. F. (2006). The good, the bad, and the ugly: An fMRI investigation of the functional anatomic correlates of stigma. Soc. Neurosci. 1, 5-15. doi: 10.1080/17470910600670579

Lee, Y.-S., Turkeltaub, P., Granger, R., and Raizada, R. D. (2012). Categorical speech processing in Broca's area: an fMRI study using multivariate pattern-based analysis. J. Neurosci. 32, 3942-3948. doi: 10.1523/JNEUROSCI.3814-11.2012

Luo, Q., Nakic, M., Wheatley, T., Richell, R., Martin, A., and Blair, R. J. R. (2006). The neural basis of implicit moral attitude-an IAT study using event-related fMRI. Neuroimage 30, 1449-1457. doi: 10.1016/j.neuroimage.2005.11.005

Macleod, A., and Summerfield, Q. (1987). Quantifying the contribution of vision to speech perception in noise. Br. J. Audiol. 21, 131-141. doi: 10.3109/03005368709077786

Marian, V., Blumenfeld, H. K., and Kaushanskaya, M. (2007). The Language Experience and Proficiency Questionnaire (LEAP-Q): assessing language profiles in bilinguals and multilinguals. J. Speech Lang. Hear. Res. 50, 940-967. doi: 10.1044/1092-4388(2007/067)

Matsumoto, R., Imamura, H., Inouchi, M., Nakagawa, T., Yokoyama, Y., Matsuhashi, M., et al. (2011). Left anterior temporal cortex actively engages in speech perception: a direct cortical stimulation study. Neuropsychologia 49, 1350-1354. doi: 10.1016/j.neuropsychologia.2011.01.023

Mattys, S. L., Davis, M. H., Bradlow, A. R., and Scott, S. K. (2012). Speech recognition in adverse conditions: a review. Lang. Cogn. Process. 27, 953-978. doi: 10.1080/01690965.2012.705006

Mcconnell, A. R., and Leibold, J. M. (2001). Relations among the Implicit Association Test, discriminatory behavior, and explicit measures of racial attitudes. J. Exp. Soc. Psychol. 37, 435-442. doi: 10.1006/jesp.2000.1470

McGowan, K. B. (2011). The Role of Socioindexical Expectation in Speech Perception Dissertation, University of Michigan.

Meister, I. G., Wilson, S. M., Deblieck, C., Wu, A. D., and Iacoboni, M. (2007). The essential role of premotor cortex in speech perception. Curr. Biol. 17, 1692-1696. doi: 10.1016/j.cub.2007.08.064

Minear, M., and Park, D. C. (2004). A lifespan database of adult facial stimuli. Behav. Res. Methods Instrum. Comput. 36, 630-633. doi: 10.3758/BF032 06543

Molnar-Szakacs, I., Iacoboni, M., Koski, L., and Mazziotta, J. C. (2005). Functional segregation within pars opercularis of the inferior frontal gyrus: evidence from fMRI studies of imitation and action observation. Cereb. Cortex 15, 986-994. doi: 10.1093/cercor/bhh199

Morosan, P., Rademacher, J., Schleicher, A., Amunts, K., Schormann, T., and Zilles, K. (2001). Human primary auditory cortex: cytoarchitectonic subdivisions and mapping into a spatial reference system. Neuroimage 13, 684-701. doi: 10.1006/nimg.2000.0715

Möttönen, R., Krause, C. M., Tiippana, K., and Sams, M. (2002). Processing of changes in visual speech in the human auditory cortex. Brain Res. Cogn. Brain Res. 13, 417-425. doi: 10.1016/S0926-6410(02)00053-8

Mumford, J. (2007). A Guide to Calculating Percent Change With Featquery. Unpublished Tech Report. Available online at: http://mumford.bol.ucla.edu/perchange_guide.pdf

Munro, M. J., and Derwing, T. M. (1995a). Foreign accent, comprehensibility, and intelligibility in the speech of second language learners. Lang. Learn. 45, 73-97. doi: 10.1111/j.1467-1770.1995.tb00963.x

Munro, M. J., and Derwing, T. M. (1995b). Processing time, accent, and comprehensibility in the perception of native and foreign-accented speech. Lang. Speech 38, 289-306.

Munro, M. J., and Derwing, T. M. (2001). Modeling perceptions of the accentedness and comprehensibility of L2 speech the role of speaking rate. Stud. Second Lang. Acq. 23, 451-468.

Myers, E. B., Blumstein, S. E., Walsh, E., and Eliassen, J. (2009). Inferior frontal regions underlie the perception of phonetic category invariance. Psychol. Sci. 20, 895-903. doi: 10.1111/j.1467-9280.2009.02380.x
Narain, C., Scott, S. K., Wise, R. J., Rosen, S., Leff, A., Iversen, S., et al. (2003). Defining a left-lateralized response specific to intelligible speech using fMRI. Cereb. Cortex 13, 1362-1368. doi: 10.1093/cercor/bhg083

Neubauer, A. C., and Fink, A. (2009). Intelligence and neural efficiency. Neurosci. Biobehav. Rev. 33, 1004-1023. doi: 10.1016/j.neubiorev.2009.04.001

Nichols, T. E., and Holmes, A. P. (2002). Nonparametric permutation tests for functional neuroimaging: a primer with examples. Hum. Brain Mapp. 15, 1-25. doi: 10.1002/hbm. 1058

Niedzielski, N. (1999). The effect of social information on the perception of sociolinguistic variables. J. Lang. Soc. Psychol. 18, 62-85. doi: 10.1177/0261927X99018001005

Okada, K., Rong, F., Venezia, J., Matchin, W., Hsieh, I.-H., Saberi, K., et al. (2010). Hierarchical organization of human auditory cortex: evidence from acoustic invariance in the response to intelligible speech. Cereb. Cortex 20, 2486-2495 doi: 10.1093/cercor/bhp318

Peelle, J. E., McMillan, C., Moore, P., Grossman, M., and Wingfield, A. (2004) Dissociable patterns of brain activity during comprehension of rapid and syntactically complex speech: evidence from fMRI. Brain Lang. 91, 315-325. doi: 10.1016/j.bandl.2004.05.007

Pekkola, J., Ojanen, V., Autti, T., Jääskeläinen, I. P., Möttönen, R., Tarkiainen, A., et al. (2005). Primary auditory cortex activation by visual speech: an fMRI study at 3 T. Neuroreport 16, 125-128. doi: 10.1097/00001756-200502080-00010

Powell, M. J. (2009). The BOBYQA Algorithm for Bound Constrained Optimization Without Derivatives. Cambridge NA Report NA2009/06. Cambridge: University of Cambridge.

Pulvermüller, F. (2005). Brain mechanisms linking language and action. Nat. Rev. Neurosci. 6, 576-582. doi: 10.1038/nrn1706

Pulvermüller, F., and Fadiga, L. (2010). Active perception: sensorimotor circuits as a cortical basis for language. Nat. Rev. Neurosci. 11, 351-360. doi: $10.1038 / \mathrm{nrn} 2811$

Pulvermüller, F., Hauk, O., Nikulin, V. V., and Ilmoniemi, R. J. (2005). Functional links between motor and language systems. Eur. J. Neurosci. 21, 793-797. doi: 10.1111/j.1460-9568.2005.03900.x

Pulvermüller, F., Huss, M., Kherif, F., Del Prado Martin, F. M., Hauk, O., and Shtyrov, Y. (2006). Motor cortex maps articulatory features of speech sounds. Proc. Natl. Acad. Sci. U.S.A. 103, 7865-7870. doi: 10.1073/pnas.0509 989103

Rauschecker, J. P., and Scott, S. K. (2009). Maps and streams in the auditory cortex: nonhuman primates illuminate human speech processing. Nat. Neurosci. 12, 718-724. doi: 10.1038/nn.2331

Recanzone, G. A., Schreiner, C., and Merzenich, M. M. (1993). Plasticity in the frequency representation of primary auditory cortex following discrimination training in adult owl monkeys. J. Neurosci. 13, 87-103.

Richeson, J. A., Baird, A. A., Gordon, H. L., Heatherton, T. F., Wyland, C. L., Trawalter, S., et al. (2003). An fMRI investigation of the impact of interracial contact on executive function. Nat. Neurosci. 6, 1323-1328. doi: 10.1038/nn1156

Ross, L. A., Saint-Amour, D., Leavitt, V. M., Javitt, D. C., and Foxe, J. J. (2007) Do you see what I am saying? Exploring visual enhancement of speech comprehension in noisy environments. Cereb. Cortex 17, 1147-1153. doi: 10.1093/cercor/bhl024

Rypma, B., Berger, J. S., Prabhakaran, V., Martin Bly, B., Kimberg, D. Y., Biswal, B. B., et al. (2006). Neural correlates of cognitive efficiency. Neuroimage 33, 969-979. doi: 10.1016/j.neuroimage.2006.05.065

Sams, M., Aulanko, R., Hämäläinen, M., Hari, R., Lounasmaa, O. V., Lu, S.-T., et al (1991). Seeing speech: visual information from lip movements modifies activity in the human auditory cortex. Neurosci. Lett. 127, 141-145. doi: 10.1016/03043940(91)90914-F

Schmid, P. M., and Yeni-Komshian, G. H. (1999). The effects of speaker accent and target predictability on perception of mispronunciations. J. Speech Lang. Hear Res. 42, 56-64. doi: 10.1044/jslhr.4201.56

Scott, S. K., Blank, C. C., Rosen, S., and Wise, R. J. (2000). Identification of a pathway for intelligible speech in the left temporal lobe. Brain 123, 2400-2406. doi: 10.1093/brain/123.12.2400

Sidaras, S. K., Alexander, J. E., and Nygaard, L. C. (2009). Perceptual learning of systematic variation in Spanish-accented speech. J. Acoust. Soc. Am. 125, 3306-3316. doi: 10.1121/1.3101452

Skipper, J. I., Nusbaum, H. C., and Small, S. L. (2005). Listening to talking faces: motor cortical activation during speech perception. Neuroimage $25,76-89$. doi: 10.1016/j.neuroimage.2004.11.006 
Smith, S. M. (2002). Fast robust automated brain extraction. Hum. Brain Mapp. 17, 143-155. doi: 10.1002/hbm.10062

Smith, S. M., Jenkinson, M., Woolrich, M. W., Beckmann, C. F., Behrens, T. E., Johansen-Berg, H., et al. (2004). Advances in functional and structural MR image analysis and implementation as FSL. Neuroimage 23, S208-S219. doi: 10.1016/j.neuroimage.2004.07.051

Strainer, J. C., Ulmer, J. L., Yetkin, F. Z., Haughton, V. M., Daniels, D. L., and Millen, S. J. (1997). Functional MR of the primary auditory cortex: an analysis of pure tone activation and tone discrimination. Am. J. Neuroradiol. 18, 601-610.

Strand, E. A. (1999). Uncovering the role of gender stereotypes in speech perception. J. Lang. Soc. Psychol. 18, 86-100. doi: 10.1177/0261927X990180 01006

Sumby, W. H., and Pollack, I. (1954). Visual contribution to speech intelligibility in noise. J. Acoust. Soc. Am. 26, 212-215. doi: 10.1121/1.1907309

Suslow, T., Kugel, H., Reber, H., Bauer, J., Dannlowski, U., Kersting, A., et al. (2010). Automatic brain response to facial emotion as a function of implicitly and explicitly measured extraversion. Neuroscience 167, 111-123. doi: 10.1016/j.neuroscience.2010.01.038

Tajima, K., Port, R., and Dalby, J. (1997). Effects of temporal correction on intelligibility of foreign-accented English. J. Phon. 25, 1-24. doi: 10.1006/jpho.1996.0031

Van Wassenhove, V., Grant, K. W., and Poeppel, D. (2005). Visual speech speeds up the neural processing of auditory speech. Proc. Natl. Acad. Sci. U.S.A. 102, 1181-1186. doi: 10.1073/pnas.0408949102

Van Wijngaarden, S. J. (2001). Intelligibility of native and non-native Dutch speech. Speech Commun. 35, 103-113. doi: 10.1016/S0167-6393(00)00098-4

Wilson, S. M., and Iacoboni, M. (2006). Neural responses to non-native phonemes varying in producibility: evidence for the sensorimotor nature of speech perception. Neuroimage 33, 316-325. doi: 10.1016/j.neuroimage.2006.05.032
Winkler, I., Denham, S. L., and Nelken, I. (2009). Modeling the auditory scene: predictive regularity representations and perceptual objects. Trends Cogn. Sci. 13, 532-540. doi: 10.1016/j.tics.2009.09.003

Wong, P. C., Uppunda, A. K., Parrish, T. B., and Dhar, S. (2008). Cortical mechanisms of speech perception in noise. J. Speech Lang. Hear. Res. 51, 1026-1041. doi: 10.1044/1092-4388(2008/075)

Woolrich, M. W., Jbabdi, S., Patenaude, B., Chappell, M., Makni, S., Behrens, T., et al. (2009). Bayesian analysis of neuroimaging data in FSL. Neuroimage 45, S173-S186. doi: 10.1016/j.neuroimage.2008.10.055

Yi, H., Phelps, J. E., Smiljanic, R., and Chandrasekaran, B. (2013). Reduced efficiency of audiovisual integration for nonnative speech. J. Acoust. Soc. Am. 134, EL387-EL393. doi: 10.1121/1.4822320

Conflict of Interest Statement: The authors declare that the research was conducted in the absence of any commercial or financial relationships that could be construed as a potential conflict of interest.

Received: 23 May 2014; accepted: 10 September 2014; published online: 08 October 2014

Citation: Yi H, Smiljanic $R$ and Chandrasekaran B (2014) The neural processing of foreign-accented speech and its relationship to listener bias. Front. Hum. Neurosci. 8:768. doi: 10.3389/fnhum.2014.00768

This article was submitted to the journal Frontiers in Human Neuroscience.

Copyright (c) 2014 Yi, Smiljanic and Chandrasekaran. This is an open-access article distributed under the terms of the Creative Commons Attribution License (CC BY). The use, distribution or reproduction in other forums is permitted, provided the original author(s) or licensor are credited and that the original publication in this journal is cited, in accordance with accepted academic practice. No use, distribution or reproduction is permitted which does not comply with these terms. 